\title{
Lazer Tabanlı Hava Hızı Ölçüm Yöntemlerinin Araştırılması
}

\author{
Atıf Kerem Şanl $1^{1}$, Timuçin Emre Tabaru ${ }^{2,3 *}$

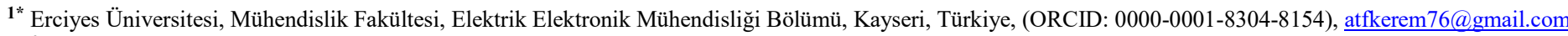 \\ ${ }^{2}$ Sivas Bilim ve Teknoloji Üniversitesi, Mühendislik ve Doğa Bilimleri Fakültesi, Elektrik Elektronik Mühendisliği Bölümü, Sivas, Türkiye (ORCID: 0000-0002- \\ 1373-3620), etabaru@sivas.edu.tr \\ ${ }^{3}$ Erciyes Üniversitesi, Klinik Araştırma ve Uygulama Merkezi, Kayseri, Türkiye
}

(Uluslararası Araştırma-Geliştirme ve Tasarım Konferansı - 15-18 Aralık 2021)

(DOI: $10.31590 /$ josat.1040180)

ATIF/REFERENCE: Şanlı, A. K. \& Tabaru T. E. (2021). Lazer Tabanlı Hava Hızı Ölçüm Yöntemlerinin Araştırılması. Avrupa Bilim ve Teknoloji Dergisi, (32), 1070-1075.

$\ddot{O} \mathbf{z}$

Hava hızı; karasal, deniz, uzay ve havacılıktaki pek çok uygulamalarda kritik öneme sahip bir parametredir. Özellikle uçaklarda bu parametrenin hesaplanması ile türbülans, rüzgâr kesmesi gibi olaylar önceden tahmin edilebilir ve buna yönelik önlem alınabilir. Hava hızının ölçümünde kullanılan geleneksel ve lazer tabanlı teknikleri, çalışma detayları ile örnek sistem tasarımları araştırılmıştır. Ayrıca Light Detection and Ranging (LIDAR) teknolojisinin bu teknikler içerisinde edindiği yer çalışmamızda incelenmiştir. Ek olarak, hava hızı ölçümünde önemli üstünlükleri olan UV Doppler LIDAR'ın, avantajları ve tasarım karakteristikleri araştırılmıştır.

Anahtar Kelimeler: Hava hızı ölçümü, Doppler etkisi, UV LIDAR, Aerosol.

\section{Investigation of Laser Based Air Speed Measurement Methods}

\begin{abstract}
Airspeed is a critical parameter in many applications in terrestrial, marine, space, and aviation. Especially in airplanes, by calculating this parameter, events such as turbulence and wind shear can be predicted, and precautions can be taken. In this study, traditional and laser-based techniques used in the measurement of air velocity, working details and sample system designs were investigated. In addition, the importance of Light Detection and Ranging (LIDAR) technology in these techniques has been examined. In addition, the advantages and design characteristics of UV Doppler LIDAR, which has significant advantages in air velocity measurement, are investigated.
\end{abstract}

Keywords: Airspeed measurement, Doppler effect, UV LIDAR, Aerosol.

\footnotetext{
* Sorumlu Yazar: etabaru@sivas.edu.tr
} 


\section{Giriş}

Karasal alanlarda [1], uçaklarda ve uzay uygulamalarında [2], [3], gemilerde ve açık deniz platformlarında, hava hızı ölçümleri operasyon ve güvenlik açısından son derece önemlidir [4], [5] ve bazen sayısal hava tahmininde kullanılmak üzere meteoroloji servislerine de bildirilir.

Hava hızını (bir uçağın çevresindeki havaya göre hızı) izlemenin geleneksel yolu, Şekil 1' de görülen hava akışını işaret eden uçağa bağlı silindirik pitot tüpleridir [6]. Pitot tüpleri, ileri hava basıncı ile hareket yönüne dik açılarda hava basıncını veya statik hava basıncını ölçerek bu basınçlar arasındaki farkı hava hızını hesaplamak için kullanır. Pitot tüpleri yüksek hızlarda kendini kanıtlamış hassas bir ekipmandır ancak düşük hızlarda ileri ve statik basınç farklarını çözme yetenekleri oldukça düşüktür. $\mathrm{Bu}$, düşük hızlarda hava hızının ölçülmesini son derece zorlaştırır ve özellikle yere yakın düşük hızlı manevralar sırasında hava araçları için ciddi bir sorun haline gelir. Çünkü pitot tüpleri ile geriye doğru bir uçuş sırasında meydana gelen negatif hız kesinlikle ölçülemez. Ek olarak, pitot tüpleri gövdeden dişarı çıkarak sürtünmeye ve buna bağlı olarak yakıt tüketiminde artışa neden olur. Uzun mesafeli bir uçağın 20 ila 25 yıllık ömrü boyunca bu son derece önemlidir, bu nedenle düşük sürtünmeli veya ideal olarak sürtünmesiz herhangi bir hava hızı algılama tekniğinin yanı sıra bu operasyonel sınırlamaların üstesinden gelmek faydalı olacaktır.

Günümüzde pitot tüplerine alternatif olarak güncel hava araçlarında lazer tabanlı hava hızı tespit sistemleri kullanılmaya başlanmıştır. Bu sistemlerin kullanımında bir dizi önemli fayda ortaya çıkmaktadır. Bunlardan bazıları; düşük hızlı faaliyetler sırasında pilotlara sağlanan bilgileri büyük ölçüde geliştirmek ve potansiyel olarak güvenliği artırmaktır. Sabit kanatlı yolcu ve nakliye uçakları için, pitot tüplerinin ortadan kaldırılmasıyla elde edilen sürtünme azalması, uzun yolculuklarda yakıt tasarrufu sağlayacaktır.

Lazer tabanlı sistemlerin sağladığı "yönlendirme" yeteneği, doğru vektör ölçümlerinin alınmasını sağlayarak uçuş kontrolünü iyileştirecek ve askeri uçaklar için radar bölgesinde kaldıkları zamanı azaltarak düşman topraklarında hayatta kalma şanslarını artıracaktır. Ayrıca sistemin potansiyel olarak yüksek güvenilirliği, pitot tüpleriyle ilişkili bakım maliyetlerini de azaltacaktır.

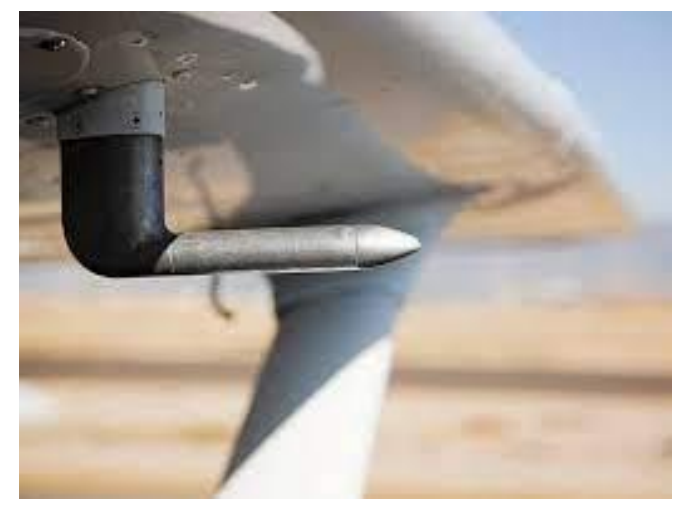

Şekil 1. Uçaklarda Kullanılan Pitot Tüpleri [6].

Bu çalışmada, hava hızının ölçümünde kullanılan geleneksel ve lazer tabanlı teknikleri, bu tekniklerin çalışma detayları ile örnek sistem tasarımlarını ve LIDAR teknolojisinin bu teknikler içerisinde edindiği yeri araştırılmıştır.

\section{Hava Hızı Ölçümlerinde Lidar Kullanımı}

Lazer-radarlar olarak da bilinen lidarlar, optik uzaktan algılama sistemleridir. Yani bilgiyi elde etmek için araç olarak 1şığ1 kullanır ve uzaktaki nesneleri böylece keşfederler. Bu çalışma biçimleri ile karanlık bir odayı aydınlatmak için kullanılan el fenerine benzerler. Lidar tekniklerinin kökenleri ve temeli, ilk olarak savaşlar arası dönemde radar sistemlerinin geliştirilmesiyle ortaya çıkmıştır. Lidarların atası, radyo iletişim teknolojisinin uzaktan algılama alanındaki bir uygulaması olan radarlar, hedefler hakkında bilgi elde etmek için radyo frekansı aralığında yankı lokalizasyonu kullanmaktadır. 20. yüzyılın 60'lı yıllarında, lazerlerin icadı ve optoelektroniklerin gelişimiyle beraber, bu tekniklerin optik frekanslara verimli bir şekilde uyarlanması için gereken teknolojiler sağlanmıştır. Aslında, her iki isim de: lazer-radar ve lidar- ki bu Işsk Algılama ve Menzillendirme'nin (Light Detection And Ranging) kısaltmasıdır (ilk olarak radarlar için kullanılanın optik bir versiyonu: Radyo Algılama ve Menzillendirme [Radio Detection And Ranging])- bu mirası güzel bir şekilde ortaya koymaktadır [7].

Lazer radarlar tarafindan kullanılan dalga boyları aralığı, uygulamaların çoğunda ultraviyole (UV), görünür ve yakın kızılötesi (NIR) frekans bantlarında yer alır ve uzaktan algılama araçları olarak sahip oldukları benzersiz özelliklerin bazılarını bu şekilde alırlar. $\mathrm{Bu}$ frekanslarda, elektromanyetik 1 şınım atmosferik bileşenlerle güçlü bir şekilde etkileşir. Bu etkileşimden yararlanan lidarlar, atmosfer durumunun menzil çözümlü bilgilerini elde etmek için kullanılabilir. Böylece atmosfer bilimi lidar teknolojilerinin ana uygulama alanlarından biri olarak karşımıza çıkar. Atmosferik dinamiklerini yöneten karmaşık süreçleri anlamak ve modellemek için kritik öneme sahip olan sıcaklık, basınç, rüzgâr hızı, aerosol parçacıklarının yoğunluğu, su buharı ve eser gazlar gibi bir dizi atmosferik değişken, lidar enstrümanları kullanılarak başarılı bir şekilde ölçülmüştür. Kullanılan bu enstrümanların başında da Doppler etkisine dayanarak hesaplama yapan Doppler Rüzgâr Lidarları gelmektedir.

\section{Doppler Rüzgâr Lidar Yöntemi}

Deney ve saha çalışmalarında kullanılan başlıca lidarlardan biri, Doppler etkisine dayanarak ışınım esnasında oluşan frekans kaymalarına göre hesaplama yapan Doppler rüzgâr lidarlarıdır. Doppler rüzgâr lidarları, aerosoller ve rüzgâr izleyicisi olarak alınan hava molekülleri tarafindan saçılan ışı̆̆ın, lazer ışınımı ile aydınlatıldıklarında uğradıkları Doppler frekans kaymasını tespit eder ve bu şekilde rüzgârın hızını ölçer.

Rüzgâr hızını elde etmek için kullanılan temel ölçümle ilgili olarak, rüzgâr lidar teknikleri iki başlık altında incelenebilir: Doppler teknikleri ve doğrudan hareket algılama teknikleri. Çalışmamızda ele aldığımız Doppler teknikleri, atmosferin ana bileşen molekülleri olan $\mathrm{N}_{2}$ ve $\mathrm{O}_{2}$ 'nin, dolayısıyla rüzgârın veya rüzgâr izleyicileri olarak alınan atmosferde asılı kalan parçacıkların (aerosoller) hareketini, geri saçılım ışınımının maruz kaldığı Doppler kaymasını belirleyerek ölçer. Doppler etkisine göre, geri saçılan 1şığın frekans kayması, görüş hattı yönündeki rüzgâr hızı ile doğrudan bağlantılıdır ve bu bağlantının açıklanabilmesi için çeşitli ölçüm teknikleri kullanılmaktadır. 


\subsection{Doppler Lidarları'nda Kullanılan Ölçüm Teknikleri}

Doppler teknikleri, tutarlı ve doğrudan algılama teknikleri olarak kendi içinde iki sınıfa ayrılabilir. Tutarlı sistemler, Doppler kaymasın1, optik alan radyo frekans1 radar tekniklerine göre tahminde bulunan heterodin tekniklerini kullanarak ölçer. Çalışmaları, geniş bantlı bir optik detektör üzerinde, dönüş sinyalini frekansa kararlı bir yerel osilatör (bir lazer ışını) ile karıştırmaya dayanır; elde edilen ara frekans sinyali, spektral tepe noktasının tahmin edilmesi için işlenir. Bu teknik, gelişmiş foto alıcı duyarlılı̆̆ 1 ve yüksek hassasiyet sunar, ancak çalışması moleküler dönüşün zayıf olduğu kızılötesi bölge ile sınırlıdır ve sonuç olarak uygulanabilirliği, temel olarak gezegen sınır tabakası içinde yüksek aerosol içeriğine sahip bölgelerle sınırlıdır.

Doğrudan algılama tabanlı Doppler rüzgâr lidarları, tutarlı sistemlerin aksine, algılamadan önce dönüş optik sinyalini spektral olarak çözmek için optik frekans ayırıcılarını kullanır. Bu durumda, moleküler dönüşün güçlü olduğu ultraviyole bölgesinde de yüksek hassasiyet ile çalışmaları mümkün olur. Aerosol içermeyen koşullarda rüzgâr hızı ölçümleri bu nedenle mümkün olup, şu anda bu tekniği orta-üst troposferde ve stratosferde rüzgâr profili çıkarma için tercih edilen yöntem haline getirmektedir [7].

Bahsettiğimiz çalışma alanları ve şekilleri bakımından, Doppler lidarları da kendi içlerinde bazı sınıflara ayrılır.

\subsection{Doppler Rüzgâr Lidarı Çeşitleri}

Doppler lidarlarının kendi içlerinde çeşitleri bulunmaktadır. Bunlar "Tutarlı Doppler Rüzgâr Lidarı" ve "Doğrudan Algılamalı Doppler Rüzgâr Lidarı" olmak üzere iki tanedir.

\subsubsection{Tutarlı Doppler Rüzgâr Lidarı}

Doppler Rüzgâr Lidarlarından ele aldığımız ilk çeşit olan Şekil 2' de görülen Tutarlı Doppler rüzgâr lidarları, havada asılı kalan ve rüzgâr tarafindan sürüklenen parçacıklar tarafından geri saçılan dönüşs sinyalindeki Doppler kaymasını ölçmek için klasik radyo frekansı heterodin algılama tekniklerini optik frekanslara uyarlarlar. Hem spektral saflığını vericiye aktarmak için hem de heterodin tespiti için gereken yerel osilatör olarak frekans kararl, dar bantlı, sürekli dalga üreten bir referans lazeri kullanılır. Doppler kayması tespitinin çözünürlüğünü belirlediği için hem vericide hem de referans lazerde yüksek spektral saflık son derece önemlidir. Ölçümlerde doğruluk elde etmek için frekans kararlılığı da aynı şekilde önemlidir. Toplanan dönüş sinyali ve referans lazer 1şını arasındaki optik karışım, genellikle bir fotodiyot veya bir fotoçoğaltıcı gibi bir fotodedektörün aktif yüzeyi üzerinde dalga cephelerinin üst üste yerleştirilmesiyle elde edilir. Frekanslar yeterince yakınsa, algılanan darbe sinyali elektriksel olarak yükseltilebilir, düşük geçişli olarak filtrelenebilir ve devamında işlenebilir.

Tutarlı optik algılamanın en önemli özelliklerinden biri gelişmiş hassasiyettir. Ancak daha önce de bahsettiğimiz gibi bu durum, havadaki aerosol yoğunluğu ile doğrudan ilişkilidir, dolayısıyla aerosol yoğunluğunun düşmesiyle beraber ölçüm menzili ve hassasiyet de buna bağlı olarak düşer [8], [9]. Bu yüzden Tutarlı Doppler Rüzgâr Lidarlarının çalışma alanı, aerosol dönüşünün baskın olduğu, kabaca 1 ile $10 \mu \mathrm{m}$ arasında olan kızılötesi bölgeyle sınırlıdır. Bu nedenle tutarlı algılama, düşük irtifalarda çalışacak olan Doppler rüzgâr lidarlarında yaygın olarak kullanılan ve aerosol konsantrasyonunun yüksek olduğu alt troposferdeki kıtasal bölgelerin çoğunda ölçümler için tercih edilen bir tekniktir [10], [11], [12].

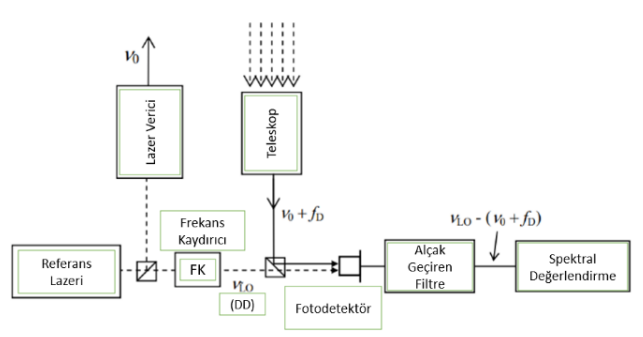

Şekil 2: Tutarlı Doppler Rüzgâr Lidarı tasarım şeması [7]

\subsubsection{Doğrudan Algılamalı Doppler Rüzgâr Lidarı}

İkinci çeşit olarak incelediğimiz doğrudan algılamalı Doppler rüzgâr lidarları, tutarlı sistemlerin aksine, dönüş sinyalindeki Doppler kaymasını ölçmek için frekans analizinden önce optik heterodin karışımını kullanmaz. Bunun yerine toplanan ışık, algılama yapılmadan önce optik frekans ayırıcılar kullanılarak spektral biçimde analiz edilir [13], [14], [15]. Doğrudan algılama sistemlerinde iki temel tipte frekans ayırıcı kullanılmaktadır. Birinci grup, Fabry-Perot interferometreleri [16] gibi yüksek çözünürlüklü optik filtrelerden veya frekans tepkilerinin tespit edilen optik yoğunluktaki değişikliklere frekans kaymalarını dönüştürmek için kullanıldığı moleküler absorpsiyon hatlarına dayalı filtrelerden oluşur.

İkinci grup ise bir doğrudan algılayıcı sistemidir ve frekans ayırıcı olarak saçak desenli görüntüleme araçlarını kullanır. $\mathrm{Bu}$ tekniği kullanan sistemler, girişim desenini optik bir interferometreden çok kanallı bir dedektöre yansıtarak geri saçılan Doppler kaymasını analiz eder. Doppler kayması, kenar konumlarının açısal yer değiştirmesinin ölçülmesiyle elde edilmiş olunur.

Doğrudan algılamalı Doppler rüzgâr lidarları, ultraviyole bölgesinde çalışmaya uygundur ve bu nedenle aerosol içermeyen koşullarda ölçüm yapabilir. $\mathrm{Bu}$, tutarlı algılamaya dayalı lidarlara göre ana avantajları olarak öne çıkmakta ve onları uzay istasyonlardan küresel ölçekli rüzgâr alanlarını ölçmek ve stratosferik rüzgâr profilini belirlemek için iyi bir seçenek haline getirmektedir. Bununla birlikte, tüm doğrudan algılama teknikleri aerosol yoğunluğunun baskın olduğu yerler için de uygulanabilir. Aerosol yüklü bölgelerde performansları tutarlı sistemlerden daha düşük olmasına rağmen, moleküler ölçümlere kolayca uyum sağlayabilme esnekliği ve daha kısa darbe kullanma olasıllı̆̆ gibi bazı avantajlar, onları ilgi çekici bir seçenek haline getirebilir. $\mathrm{Bu}$ sebeplerden dolayı, kullanılacak olan lidarın belirlenmesinde ve tasarımının yapılmasında, lazer ışığının atmosferdeki saçılma hareketlerinin iyice anlaşılması gerekir.

\subsection{Atmosferdeki Işı̆̆ın Elastik Saçılması}

Lidar sistemleri, atmosfer bir lazer ışını ile aydınlatıldığında saçılan elektromanyetik enerjiyi analiz ederek atmosferin durumu hakkında bilgi edinir. Toplam saçılan enerji üzerinde oluşan farklı katkılar, bundan sorumlu olan fiziksel olgunun özelliklerine bağlı olarak tanımlanabilir ve sınıflandırılabilir [17]. Elastik saçılma ile, gelen fotonların enerjisinin ve dolayısıyla frekanslarının korunduğu ve sadece yönlerinin değiştiği anlaşılır. Elastik saçılma Mie ve Rayleigh saçılması olarak iki sınıfa ayrılabilir. Bunlardan 
ilki olan Mie saçılması, boyutu gelen ışınımın dalga boyundan daha büyük veya karşılaştırılabilir olan aerosol parçacıklarındaki elastik saçılma anlamına gelirken, Rayleigh saçılması atmosferin bileşenlerinin molekülleri (ağırlıklı olarak O2 ve N2) dahil olmak üzere, boyutu incelenen dalga boyundan çok daha küçük olan parçacıklarda üretilir. Doppler rüzgâr lidarları, hava molekülleri veya asılı parçacıklar tarafindan elastik olarak saçılan ışınımın maruz kaldığı Doppler etkisinden dolayı frekans kaymasını tespit ederek rüzgâr hızını ölçer. Herhangi bir Doppler rüzgâr lidarının doğru bir analizi ve tasarımı, elastik saçılma nedeniyle dönüş sinyalinin ana özelliklerinin dikkate alınmasını gerektirir [7]. Çalışmamızda ele aldığımız UV Doppler Lidarı da aynı şekilde bahsettiğimiz bu detaylar ele alınarak tasarlanmaktadır.

\section{UV Doppler Lidar}

Daha önce bahsettiğimiz gibi, bir hava aracının önündeki hava akışının doğru ölçümü, modern yüksek performanslı askerisivil uçak ve helikopterler için çok önemli bir işlevdir. Askeri uçaklar için, gerçek 3B hava hızı vektörünün tam değeri, özellikle itme vektörü kontrolü ve uçuş kontrol sistemi için önemli bir değerdir. Sivil hava taşıtlarında, uçağın önündeki aerodinamiğin ölçümü, kalibrasyon uçuş testi, aerodinamik akışın haritalanması, aerodinamik akıştaki geçişlerin (Rüzgârlar, türbülanslar) tespiti ve diğer uygulamalar için de aynı şekilde önemlidir.

$\mathrm{Bu}$ tür uygulamalar için sıklıkla tutarlı Doppler LIDAR'lar önerilmiştir. NASA ve Coherent Technologies gibi çeşitli ABD şirketleri ve kurumları, 2 mikronda IR lazerler kullanarak Boeing tarafindan geliştirilen ve uçuş testi yapılan prototiplerle birlikte çalışmıştır [18]. M-FLAME ve I-WAKE gibi birkaç Avrupa programı, 1.5 mikron lazerlerin araştırılması da dahil olmak üzere benzer sistemlerin geliştirilmesini desteklemektedir. Ancak bu yaklaşımlar aşağıdaki sorunlardan dolayı adlandırılmış uygulamaların çoğu için uygun değildir:

- Tutarlı algılama, alınan sinyalin dar bir çizgi genişliğini ve dolayısıyla lazer darbelerinin aerosoller tarafindan geri saçılmasını gerektirir. Bununla birlikte, tüm küresel bölgelerde ve daha yüksek uçuş seviyelerinde yeterince yüksek bir aerosol yoğunluğu mevcut değildir. $\mathrm{Bu}$ nedenle böyle bir sistem, tüm uçuş koşulları altında sinyal üretemeyecektir.

- Darbeli tutarlı sistemler düşük darbe tekrarlama oranları ile uzun darbeler (tipik olarak $\geq 400 \mathrm{~ns}$ ) üretir, bu da zayıf bir uzunlamasına ve zamansal çözünürlükle sonuçlanır. Bu nedenle bu sensör prensibi, uzun menzilli uyarı sistemleri için uygundur ancak yüksek boylamsal çözünürlüğe sahip kısa menzilli ölçümler için uygun değildir. Güvenlik açısından kritik uygulamalar için sensörün, aerosollerin yokluğunda güvenilir sinyaller üretebilmesi gerekir bu nedenle moleküler bir geri saçılım sistemi olmalıdır.

Bu gereksinimleri karşılamayı vaat eden sensör sistemi, doğrudan algılamalı ve kısa darbeli UV Doppler LIDAR'dır. Bu teknoloji, ABD şirketleri Ophir, Michigan Aerospace ve Avrupa konsorsiyumları tarafından araştırılmıştır [19], [20].

Bahsettiğimiz sistem genel tasarım hatları ve alıcı sisteminin tanıtımıyla iki başlık altında incelenmiştir.

\subsection{UV Rüzgâr Lidarı Tasarımı}

Rüzgâr lidarı olarak geliştirilen sistem moleküler düzeyde (Rayleigh) ve devamında aerosol düzeyinde (Mie) saçılımı ölçebilmelidir. Dalga boyu kayması bir interferometrede ölçülür.
Yaklaşık $1 \mathrm{~m} / \mathrm{s}^{\prime}$ lik gerekli doğruluk, seçilen UV dalga boyu için 6 MHz'lik bir frekans kayması ile sonuçlanır. Rayleigh spektrumunun termal genişlemesi yaklaşı $600 \mathrm{~m} / \mathrm{s}^{\prime} \mathrm{dir}$. Spektrumun şekli ayrıca sıcaklık, hava basıncı ve aerosol konsantrasyonu gibi parametrelere de bağlıdır. Tam 3B rüzgâr hızı vektörünü elde etmek için Doppler kayması en az 3 yönde belirlenmelidir.

Blok şeması Şekil 3' de verilen rüzgâr lidarı olarak aday gösterilen sistemde, $355 \mathrm{~nm}$ 'de tek frekanslı üçlü Nd:YAG lazer, ışın çoğullama için bir tarama sistemi, ışın iletimi ve alımı için bir optik sistem, bir Fabry-Perot İnterferometre, bir görüntü yoğunlaştırılmış CCD kamera, bir veri kaydı ve gerçek-zaman veri işleme ünitesi ile kontrol elektroniğinden oluşmaktadır.

Tamamlanmış hali Şekil 4 'de görülen LIDAR sensörü iki aşamada gerçekleştirilmiştir. Birinci aşamada $35 \mathrm{~m}$ ileriyi görebilen bir (uçuşa uygun) sistem yapılmıştır ve uçuş testine tabi tutulmuştur. İkinci aşama ise nihai gereksinimleri karşılayacak sistemlerden oluşmaktadır. Diğer iyileştirmelerin yanı sıra, $3 \mathrm{~W}$ ortalama güçte yükseltilmiş bir lazer içerir. Bu lazer tek frekanslı, 355 nm'de çalışan, 300 mW'lık üçüncü harmonik Nd:YAG' dır. Birinci ve ikinci aşama için $3 \mathrm{~W} \mathrm{kHz}$ hızlarında $\sim 10$ ns genişliğinde darbeler yayar.

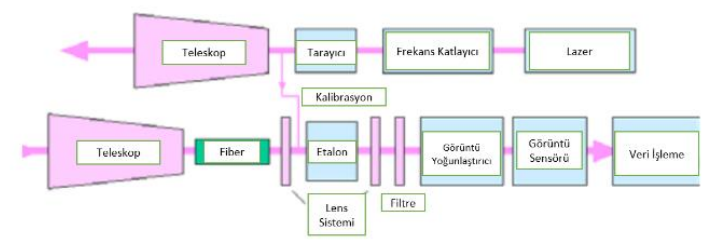

Şekil 3. Geliştirilen LIDAR sensörüne ait tasarım şeması [21]

Lazer 1şını, dört konumda sabit bir odak oluşturan bir EADS patentli tarama sistemi tarafından 4 yönde çoğullanır ve $15 \mathrm{~Hz}$ ile tam tarama tamamlanir.

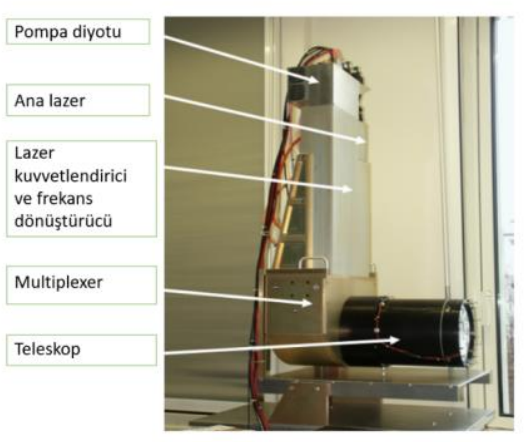

Şekil 4. Tamamlanmış UV LIDAR sensörü [21].

Alıcı yolunda, geri saçılan fotonlar dört UV lifine odaklanır ve alıcı kutusuna bağlı olan tek bir fiberde çoğullamadan arındırılır. Fabry-Perot elalon, Hovemere tarafindan tasarlanmış ve üretilmiştir. Görüntüleme Sistemi, UV duyarlı mikro kanal plakasına sahip modifiye edilmiş bir DiCAM Pro CCD kameradan oluşur. Sensör 640 x 480 piksele sahiptir ve elektronik çip üzerinde bindirme işlemi kullanılmıştır [21].

\subsection{UV Alıcı Sistem}

UV 1şınlar, hava hızı ölçümünde kritik öneme sahip olan şartları sağlamak için anahtar bir parametredir. Ancak UV 
1şınların kullanıldığg bir lidar sisteminde, beklenileceği üzere UV ışınlar ile uyumlu bir fiber alıcı sistem olmalıdır. Bunun içinse en uygun adaylardan birisi erbiyum katkılı fiber sistemdir.

Erbiyum katkılı fiberler, fiber jiroskoplarda kullanılan optik amplifikatörler veya süper lüminesans kaynaklar gibi optik cihazların önemli bir bileşenidir [22], [23]. Erbiyum katkılı fiberler aynı zamanda uzun hat veya yüksek oranda dağıtılmış telekomünikasyon sistemleri için tekrarlayıcılar olarak karasal ve denizaltı uygulamalarında da yaygın olarak kullanılırlar. Uzayda, fiberlerin uzay aracı ömrü boyunca nispeten yüksek oranda elektron ve protona maruz kalabileceği iyi bilinmektedir [24], [25], [26]. Bu nedenle, enerjik ışınımın nadir toprak katkılı lifler üzerindeki etkisi, hem ışınım ortamlarında cihaz performanslarını tahmin etmek için hem de bu malzeme sistemlerinde renk merkezi oluşumunun spesifik mekanizmalarını tanımlamak için kullanılabilir. Birkaç laboratuvar deneyi, ışınıma maruz kalmanın potansiyel olarak fiber optiğin özelliklerini farklı şekillerde etkileyebileceğini göstermiştir. Bununla birlikte çalışmaların çoğunda fiberler UV 1şığa, gama veya X-1şınları 1şınlarına maruz kaldığında, görünür ve yakın kızılötesi spektral alandaki Radyasyon Kaynaklı Zayıflama'ya (RKZ) ayrılmıştır [27], [28], [29].

Bu RKZ' nın gelişimi, özellikle erbiyum iyonları absorpsiyon bandı için $980 \mathrm{~nm}$ civarında, konak matris ve erbiyum iyonları tepkilerinin sırasıyla 1300 ve $1550 \mathrm{~nm}$ 'de kontrol edilebildiği 1250-1600 nm aralığında incelenmiştir [24], [30], [31], [32], [33]. İncelenen çeşitli parametrelerin etkisi; doz oranı, kümülatif doz, lif bileşimi (Ge, P, F, Al ve saf silika), Er3+ iyon konsantrasyonu, vb. olarak isimlendirilebilir [34], [35], [36], [37]. Ancak burada bahsedilen ölçümlerin gerçekleştirilmesinde çeşitlik zorluklar karşımıza çıkmaktadır:

1. Yakın UV aralığında yeterli seviyeye sahip güçlü bir $1 s ̧ ı k$ kaynağı gereklidir.

2. Sonda sinyali, belirli bir amaçla, çapı sadece birkaç mikron olan fiber çekirdeğe enjekte edilmelidir.

3. Kesme tekniği kullanıldığında fiber yeterince uzun olmalıdır.

4. Zayıflama katsayıları bu spektral aralıkta önemlidir.

Bu zorlukların üstesinden gelmek için UV'ye yakın görünür prob sinyalinin, fiber çekirdeğinde bulunan optik olarak aktif merkezlere atfedilen fotolüminesans ile oluşan bir inceleme tekniği geliştirilmiştir [38]. Bu fotolüminesans 1şı̆̆ı, fiber yalnızca enine bir UV-lazer maruziyetine tabi tutulduğunda oluşur ve fiber boyunca yönlendirilirek seviyesi spektroskopik ölçümler için uygunlaştırılır. Yayıcı merkezlerin fotolüminesansı ile ilişkili ilgili dalga boyu aralığında, hem UV-lazer maruziyetinin konak matris zayıflaması üzerindeki etkisi hem de erbiyum iyonlarının absorpsiyonu bu şekilde incelenebilir.

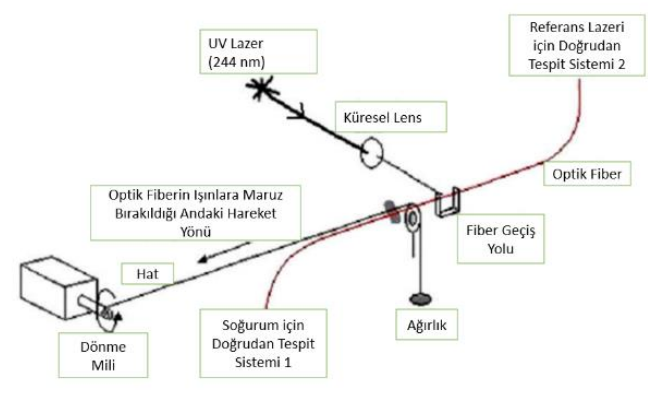

Şekil 5: UV alıcı deney sistemi [38].
Alıcıda kullanılan Şekil 5' de verilen 1558 nm'de $5.1 \mu$ m'lik bir mod alan çapına sahip Erbiyum katkılı fiberin, UV maruziyetinin gerçekleştirildiği tüm uzunluk boyunca $(20-30 \mathrm{~cm})$ yelek kısmı sıyrılmıştır. Enine 1şınlama, 244 nm'de çalışan, yaklaşık $90 \mathrm{~mW}$ 'lik bir çıkış gücü ve yaklaşık 0.5 mm'lik bir nokta boyutunda çalışan bir sürekli dalga UV-lazer ile gerçekleştirilir.

Optik ölçümler için fiberin her bir ucuna bir mini spektrometre bağlanmıştır. $\mathrm{Bu}$ aparatlar 250-850 nm spektral aralıkta bir CCD kamera ile donatılmıştır ve minimum zaman tepkileri birkaç ms mertebesindedir. UV ışınlı fiber uzunluğunu yaklaşık $20 \mathrm{~cm}$ artırmak için numuneyi lazer 1şını boyunca hareket ettirmek gerekir. $\mathrm{Bu}$ nedenle fiber, sürekli bir motor tarafından sabit bir hızda çekilebilen sıkı bir ipliğe sabitlenir. Bu yer değiştirme sırasında numune, lif ekseni boyunca homojen bir 1şınlamaya yol açan bir lif kılavuzundan geçer. $\mathrm{Bu}$ konfigürasyonda, algılama sistemi 1, numunenin 1şınlanmış kısmından geçen fotolüminesans spektrumunu kaydeder ve esas olarak absorpsiyon spektrumunun gelişimini gösterir. Bu esnada algılama sistemi 2 lazer 1şını konumunu algılar. Herhangi bir değişiklik olmadıkça sabit tutulmasına dikkat edilmelidir. $\mathrm{Bu}$ sinyal, deneyde referans olarak kullanılır. [38].

\section{Sonuç}

$\mathrm{Bu}$ çalışmada, geleneksel hava hızı ölçüm metotları, bu metotlara modern bir alternatif olan LIDAR tabanlı hava hızı ölçüm metotları, LIDAR'ların çeşitleri ve kullandıkları teknikler ile yüksek hassasiyetli bir UV Doppler LIDAR'ın özelliklerinden ve tasarımından bahsedilmiştir. IR bölgede çalışan Doppler rüzgâr LIDAR'ları, aerosol yoğunluğunun düşük olduğu alt troposferdeki kıtasal bölgelerin çoğunda ölçümler için tercih edilse de aerosol yoğunluğunun düştüğü yüksek irtifaya sahip bölgelerde beklenen sinyal değerlerini üretememektelerdir. $\mathrm{Bu}$ sebeple, moleküler düzeyde $\left(\mathrm{O}_{2}, \mathrm{~N}_{2}\right)$ ölçüm yapabilmesi sayesinde yüksek irtifalarda dahi istenilen sinyalleri üretebilen, aynı zamanda aerosol yoğunluğunun fazla olduğu düşük irtifalara da uyum sağlayabilen, yüksek hassasiyetli UV Doppler LIDAR'ın gerekliliklerine ve tasarım aşamalarına değinilmiştir.

\section{Kaynakça}

[1] Clifford, S. F., Kaimal, J. C., Lataitis, R. J., \& Strauch, R. G. (1994). Ground-based remote profiling in atmospheric studies: An overview. Proceedings of the IEEE, 82(3), 313355.

[2] Hays, P., Dehring, M., Fisk, L., Tchoryk, P., Dors, I., Ryan, J., \& Hovis, F. (2005). Space-based Doppler winds lidar: a vital national need. Response to national research council (NRC) decadal study request for information (RFI).

[3] P. Ingmann, E. Anderson, A. Dabas, M. Endemann, E. Kallen, D. Offiler and A. Stoffelen, "SP-1311, 'ADM-aeolus' april 2008," ESA Communication Production Office, 2200 AG Noordwijk. The Netherlands, Tech. Rep. SP-1311, 2008.

[4] A. Peña, C. B. Hasager, S. Gryning, M. Courtney, I. Antoniou and T. Mikkelsen, "Offshore wind profiling using light detection and ranging measurements," Wind Energy, vol. 12, pp. 105-124, 2009.

[5] F. Bingöl, J. Mann and G. C. Larsen, "Light detection and ranging measurements of wake dynamics part I: onedimensional scanning," Wind Energy, vol. 13, pp. 51-61, 2010. 
[6] Pitot Tüpleri ve Kullanımları, Wikipedia, https://en.wikipedia.org/wiki/Pitot tube.

[7] Muñoz Porcar, C. (2013). Analysis and design of an edgetechnique-based Doppler wind lidar: practical assessment of a laboratory prototype.

[8] Liu, Z. S., Chen, W. B., Zhang, T. L., Hair, J. W., \& She, C. Y. (1997). An incoherent Doppler lidar for ground-based atmospheric wind profiling. Applied Physics B: Lasers \& Optics, 64(5).

[9] Huffaker, R., \& Hardesty, R. (1996). Remote sensing of atmospheric wind velocities using solid-state and $\mathrm{CO} / \mathrm{sub}$ 2/coherent laser systems. Proceedings of the IEEE, 84(2), 181-204.

[10] Huffaker, R. M., Jelalian, A. V., \& Thomson, J. A. L. (1970). Laser-Doppler system for detection of aircraft trailing vortices. Proceedings of the IEEE, 58(3), 322-326.

[11] Post, M. J. (1994, August). Development of coherent laser radar. In Proceedings of IGARSS'94-1994 IEEE International Geoscience and Remote Sensing Symposium (Vol. 2, pp. 923-925). IEEE.

[12] Rodríguez Gómez, A. A. (1998). Sistemas lidar coherentes e incoherentes de baja potencia para la detección de velocidad de blancos sólidos. Universitat Politècnica de Catalunya.

[13] Korb, C. L., Gentry, B. M., \& Weng, C. Y. (1992). Edge technique: theory and application to the lidar measurement of atmospheric wind. Applied Optics, 31(21), 4202-4213.

[14] Abreu, V. J. (1979). Wind measurements from an orbital platform using a lidar system with incoherent detection: an analysis. Applied Optics, 18(17), 2992-2997.

[15] Benedetti-Michelangeli, G., Congeduti, F., \& Fiocco, G. (1972). Measurement of aerosol motion and wind velocity in the lower troposphere by Doppler optical radar. Journal of Atmospheric Sciences, 29(5), 906-910.

[16] Vaughan, J. M. (2017). The Fabry-Perot Interferometer: History, Theory, Practice and Applications. Routledge.

[17] Weitkamp, C. (Ed.). (2006). Lidar: range-resolved optical remote sensing of the atmosphere (Vol. 102). Springer Science \& Business.

[18] Soreide, D. C., Bogue, R. K., Ehernberger, L. J., \& Bagley, H. R. (1996, November). Coherent lidar turbulence for gust load alleviation. In Optical Instruments for Weather Forecasting (Vol. 2832, pp. 61-75). International Society for Optics and Photonics.

[19] www.ophir.com/rayleigh_mie_optical_air_data.htm

[20] http://www.michiganaero.com/moads/index.shtml

[21] Schmitt, N. P., Rehm, W., Pistner, T., Zeller, P., Diehl, H., \& Navé, P. (2007). The AWIATOR airborne LIDAR turbulence sensor. Aerospace Science and Technology, 11(7-8), 546-552.

[22] Desurvire, E. (1992). Erbium-doped fiber amplifiers in Principle and applications.

[23] Digonnet, M. J. (2001). Rare-earth-doped fiber lasers and amplifiers, revised and expanded. CRC press.

[24] Williams, G. M., Putnam, M. A., \& Friebele, E. J. (1996, October). Space radiation effects on erbium-doped fibers. In Photonics for space environments IV (Vol. 2811, pp. 30-37). International Society for Optics and Photonics.

[25] Boucher, R. H., Woodward, W. F., Lomheim, T. S., Shima, R. M., Asman, D. J., Killian, K. M., ... \& Goellner, G. J. (1996). Proton-induced degradation in interferometric fiber optic gyroscopes. Optical Engineering, 35(4), 955-976.

[26] Williams, G. M., Wright, B. M., Mack, W. D., \& Friebele, E. J. (1999, December). Projecting the performance of erbiumdoped fiber devices in a space radiation environment. In
Optical Fiber Reliability and Testing (Vol. 3848, pp. 271280). International Society for Optics and Photonics.

[27] Friebele, E. J., Sigel, G. H., \& Gingerich, M. E. (1978). Radiation response of fiber optic waveguides in the 0.4 to 1.7 $\mu$ region. IEEE Transactions on Nuclear science, 25(6), 12611266.

[28] Girard, S. (2003). Analyse de la réponse des fibres optiques soumises à divers environnements radiatifs (Doctoral dissertation, Saint-Etienne).

[29] Anghinolfi, F., Jarron, P., Martemiyanov, A. N., Usenko, E., Wenninger, H., Williams, M. C. S., \& Zichichi, A. (2004). NINO: an ultra-fast and low-power front-end amplifier/discriminator ASIC designed for the multigap resistive plate chamber. Nuclear Instruments and Methods in Physics Research Section A: Accelerators, Spectrometers, Detectors and Associated Equipment, 533(1-2), 183-187.

[30] Rose, T. S., Gunn, D., \& Valley, G. C. (2001). Gamma and proton radiation effects in erbium-doped fiber amplifiers: active and passive measurements. Journal of lightwave technology, 19(12), 1918.

[31] Bussjager, R. J., Hayduk, M. J., Johns, S. T., \& Taylor, E. W. (2001, March). Gamma-ray induced responses in an erbium doped fiber laser. In 2001 IEEE Aerospace Conference Proceedings (Cat. No. 01TH8542) (Vol. 3, pp. 3-1473). IEEE.

[32] Van Uffelen, M., Girard, S., Goutaland, F., Gusarov, A., Brichard, B., \& Berghmans, F. (2004). Gamma radiation effects in Er-doped silica fibers. IEEE Transactions on Nuclear Science, 51(5), 2763-2769.

[33] Tortech, B., Van Uffelen, M., Gusarov, A., Ouerdane, Y., Boukenter, A., Meunier, J. P., ... \& Thienpont, H. (2007). Gamma radiation induced loss in erbium doped optical fibers. Journal of non-crystalline solids, 353(5-7), 477-480.

[34] Williams, G. M., Putnam, M. A., Askins, C. G., Gingerich, M. E., \& Friebele, E. J. (1992). Radiation effects in erbiumdoped optical fibres. Electronics Letters, 28(19), 1816-1818.

[35] Lewis, R. B. J., Sikora, E. S. R., Wright, J. V., West, R. H., \& Dowling, S. (1992). Investigation of effects of gamma radiation on erbium doped fibre amplifiers. Electronics Letters, 28(17), 1589-1591.

[36] Digonnet, M. J. (2001). Rare-earth-doped fiber lasers and amplifiers, revised and expanded. CRC press.

[37] Fukuda, C., Chigusa, Y., Kashiwada, T., Onishi, M., Kanamori, H., \& Okamoto, S. (1994). $\gamma$-ray irradiation durability of erbium-doped fibres. Electronics Letters, 30(16), 1342-1344.

[38] Tortech, B., Ouerdane, Y., Boukenter, A., Meunier, J. P., Girard, S., Van Uffelen, M., ... \& Thienpont, H. (2009). Transverse UV-laser irradiation-induced defects and absorption in a single-mode erbium-doped optical fiber. Optical Materials, 31(9), 1296-1299. 